\title{
Optimal treatment of social phobia: systematic review and meta-analysis
}

\author{
This article was published in the following Dove Press journal: \\ Neuropsychiatric Disease and Treatment \\ 2 May 2012 \\ Number of times this article has been viewed
}

\author{
John Canton \\ Kate M Scott \\ Paul Glue \\ Department of Psychological \\ Medicine, Dunedin School of \\ Medicine, University of Otago, \\ Dunedin, New Zealand
}

Correspondence: Paul Glue School of Medical Sciences, University of Otago, PO Box 913, Dunedin, New Zealand

Tel +64 2I 2433372

Fax +64 34747934

Email paul.glue@otago.ac.nz

\begin{abstract}
This article proposes a number of recommendations for the treatment of generalized social phobia, based on a systematic literature review and meta-analysis. An optimal treatment regimen would include a combination of medication and psychotherapy, along with an assertive clinical management program. For medications, selective serotonin reuptake inhibitors and dual serotonin-norepinephrine reuptake inhibitors are first-line choices based on their efficacy and tolerability profiles. The nonselective monoamine oxidase inhibitor, phenelzine, may be more potent than these two drug classes, but because of its food and drug interaction liabilities, its use should be restricted to patients not responding to selective serotonin reuptake inhibitors or serotonin-norepinephrine reuptake inhibitors. There are other medication classes with demonstrated efficacy in social phobia (benzodiazepines, antipsychotics, alpha-2-delta ligands), but due to limited published clinical trial data and the potential for dependence and withdrawal issues with benzodiazepines, it is unclear how best to incorporate these drugs into treatment regimens. There are very few clinical trials on the use of combined medications. Cognitive behavior therapy appears to be more effective than other evidence-based psychological techniques, and its effects appear to be more enduring than those of pharmacotherapy. There is some evidence, albeit limited to certain drug classes, that the combination of medication and cognitive behavior therapy may be more effective than either strategy used alone. Generalized social phobia is a chronic disorder, and many patients will require long-term support and treatment.
\end{abstract}

Keywords: social phobia, social anxiety disorder, psychotherapy, cognitive behavior therapy, antidepressant

\section{Introduction}

Social phobia (also known as social anxiety disorder) is an anxiety disorder in which there is a "marked and persistent fear of social or performance situations in which embarrassment may occur". ${ }^{1}$ It was first included in the third edition of the Diagnostic and Statistical Manual of Mental Disorders (DSM) in $1980^{2}$ and is included in the section on anxiety disorders. DSM has the specifier of "generalized" relating to when fears are related to most social situations. By exclusion, the unspecified "nongeneralized" form relates to specific situations, and in the literature is often referred to as "nongeneralized social phobia". For the remainder of this article, we have chosen to focus on generalized social phobia (hereafter simply referred to as social phobia). Generalized social phobia is the more relevant disorder to general psychiatric clinical work.

Social phobia has an early onset, with the median age of onset in the National Comorbidity Survey of 16 years. ${ }^{3}$ The most commonly reported fears relate to public speaking or speaking up in a meeting or a class. ${ }^{4}$ The disorder is associated with 
significant disability. Patients with social phobia are more likely to utilize medical outpatient clinics, receive lower incomes, be less likely to earn college degrees, or attain managerial, technical, or professional occupations $s^{3,5,6}$ than people not suffering with social phobia. They are also more impaired in family relationships, romantic relationships, and desire to live, with $21.9 \%$ having attempted suicide. ${ }^{6,7}$ The course of social phobia tends to be chronic, with a long duration of illness $^{8}$ and low rates of recovery. ${ }^{9}$

Social phobia has a high degree of comorbidity with other psychiatric disorders. Eighty-one percent of people suffering from social phobia reported at least one other lifetime DSM-IIIR disorder in the National Comorbidity Survey. ${ }^{3}$ The odds ratio (OR) of having a second anxiety disorder is increased (range 7.1-8.7). ${ }^{3}$ Between $16.6 \%{ }^{10}$ and $35.8 \%{ }^{6}$ of sufferers experience major depressive disorder, with social phobia preceding the onset of major depressive disorder by 12 years. ${ }^{6}$ Rates of concurrent alcohol dependence are $27.3 \%$, and concurrent alcohol abuse occurs in $11.3 \%{ }^{6}$ to $20.9 \%{ }^{10}$ of patients with social phobia. For patients with social phobia and a comorbid alcohol misuse disorder, almost $80 \%$ developed social phobia before the alcohol misuse disorder. ${ }^{11}$ This seems to be the pattern with other comorbid conditions, with social phobia being the primary disorder in $71.4 \% .{ }^{3,6}$ Patients who have social phobia and a comorbid alcohol disorder have an increased rate of comorbid psychiatric disorders, with $97 \%$ having at least one additional Axis I disorder, and $71.7 \%$ having a personality disorder. ${ }^{11}$

Recent data from the cross-sectional World Mental Health surveys ${ }^{12}$ provide cross-national comparisons of social phobia diagnosed by DSM-IV Composite International Diagnostic Interview in the general populations of developed and developing countries. These data show great variation in 12-month prevalence. Rates are lowest in China and Japan $(0.3 \%$ and $0.5 \%$, respectively), range from $0.6 \%$ to $1.4 \%$ in European countries, and are somewhat higher in the Ukraine (1.5\%), South Africa (1.9\%), Mexico (1.9\%), and Colombia (2.8\%). Rates then jump to $5.1 \%$ in New Zealand and $6.8 \%$ in the US. Explanations for these differences are likely to include both substantive and methodological reasons. The World Mental Health survey data indicate that social phobia has one of the earliest ages of onset amongst the mental disorders and yet is also one of the most undertreated anxiety disorders. Data from the New Zealand survey, the largest of the World Mental Health collaborating surveys, show that fewer than $5 \%$ of those meeting the criteria for social phobia sought treatment in the year of onset, and only $36 \%$ of those with a lifetime diagnosis of social phobia sought treatment from a health professional at some stage. ${ }^{12}$ This latter statistic compares with $57 \%$ for generalized anxiety disorder, $63 \%$ for panic disorder, $54 \%$ for agoraphobia, and $50 \%$ for post-traumatic stress disorder.

There are a number of treatment options for social phobia, including medication, psychotherapy, and their combination. Although there have been a number of reviews of medications, ${ }^{13,14}$ psychological treatment, ${ }^{15,16}$ and combined treatments ${ }^{17,18}$ for social phobia, and the development of clinical guidelines, ${ }^{18}$ there has been no synthesis of these data to identify characteristics for optimal overall management of social phobia. Patients with social phobia are difficult to engage with psychiatric services, and to date there are no published data to identify how to improve treatment engagement or adherence. The objective of this systematic review and meta-analysis was to identify optimal treatments for social phobia, based on a systematic review of published clinical trial data.

\section{Methods}

\section{Meta-analysis of treatment trials}

We performed a systematic review and meta-analysis of clinical trials using drugs, psychotherapy, or their combination, in social phobia. For the drug trials, the search methods were intended to identify all randomized, double-blind, parallel-group treatment trials in social phobia. For the psychological treatment trials, the search aimed to identify all randomized controlled trials (RCT). The search included published and unpublished studies, electronic database searches, searches of clinical and pharmaceutical trial registers, and personal communication with study authors. Studies were identified and obtained between September 2011 and January 2012 using electronic databases (Embase [1974 to the present] and Medline [1950 to the present]); reference lists of identified articles and other electronic search tools; clinical trials websites (http://www.clinicalstudyresults.org, http://clinicaltrials.gov, http://apps.who.int/ trialsearch/); and, when required, communication with study authors. The following Boolean phrases were used when searching electronic databases and other electronic search engines: "randomized controlled trial", "treatment", "drug", "psychotherapy", "psychological treatment", "cognitive behavior therapy", "cognitive therapy", "exposure therapy", "social phobia", and "social anxiety disorder".

\section{Inclusion criteria}

We sought to identify RCT, either placebo-controlled or activecontrolled. Only publications in English were considered. 
Studies that did not include information on treatment outcome were excluded. Study participants were adults who were diagnosed with DSM-III, DSM-III-R, or DSM-IV criteria for social phobia/social anxiety disorder. Data from maintenance or discontinuation phases were not collected. We did not include trials of exploratory agents, eg, neurokinin-1 antagonists or d-cycloserine, in this review. The relevance of identified papers was initially screened using title and abstract. Full manuscripts of studies of interest were screened according to inclusion criteria. Social phobia treatment studies involving medications generally include a range of clinician-rated and patient-rated outcome measures. For this analysis, we chose one endpoint, ie, the proportion of responders based on clinician assessments. In most studies, a responder was defined as someone who achieved a score of 1 or 2 on the seven-point Clinical Global Impression of Change (CGI) scale. ${ }^{19}$ This represents a rating of score of very much or much improved (score of 1 or 2 , respectively). In four studies, response was defined as a $50 \%$ reduction in a clinician-rated instrument (eg, Liebowitz Social Anxiety Scale ${ }^{107}$ or Hamilton Anxiety Scale ${ }^{108}$ ) or, in one case, a self-rated instrument (Fear Questionnaire ${ }^{109}$. Previous meta-analyses have shown that changes in the CGI are broadly similar to changes in other clinician-rated and patient-rated instruments. ${ }^{20,21}$ The majority of comparative psychotherapy trials do not report responder rates, so a narrative review is provided.

\section{Data synthesis and analysis}

All analyses were performed using Review Manager (RevMan) 5.0 (Cochrane Collaboration, 2008; http://www. cc-ims.net/RevMan). For rates of treatment response, MantelHaenszel OR were calculated using a random effects model. The $\mathrm{I}^{2}$ statistic was used to assess heterogeneity.

\section{Results}

\section{Study identification and selection}

The search strategy identified 410 papers. Based on a review of study title and abstract, 183 were selected for detailed review. Reasons for noninclusion included ineligible study design (eg, nonblinded dosing, continuation treatment trial, crossover trial), response data not provided in results, duplicate data presentation, and review articles. Ultimately, 41 papers were selected for inclusion in the meta-analysis.

\section{Antidepressant drugs}

\section{Selective serotonin reuptake inhibitors}

This class of drugs is the most extensively tested in patients with social phobia, with 17 placebo-controlled acute treatment $\mathrm{RCT}$ reported. Almost half of the studies studied paroxetine, ${ }^{22-29}$ with 2-3 studies each for escitalopram, ${ }^{26,30}$ fluoxetine, ${ }^{31-33}$ fluvoxamine, ${ }^{34-36}$ and sertraline. ${ }^{37-39}$ The pooled OR for response to each selective serotonin reuptake inhibitor (SSRI) ranges between 1.98 for fluoxetine and 3.41 for paroxetine (Figure 1). With one exception, SSRIs had significantly greater CGI response rates compared with placebo. The single negative study (fluoxetine) ${ }^{32}$ was of adequate duration and used a high fluoxetine dose (60 mg/day), but was relatively small in size ( $\mathrm{n}=30$ per arm), and may thus have been underpowered to show a difference from placebo. There was significant heterogeneity associated with one study, ${ }^{29}$ but its exclusion in a sensitivity analysis had little effect on the pooled OR for paroxetine studies (3.43 decreased to 3.09). In general, SSRIs showed separation from placebo by weeks 4-6 on a number of response or other outcome measures, however SSRI-placebo differences tended to increase out to 12 weeks of treatment. There have been four studies assessing the effect of continuation treatment with SSRIs in patients who have responded to acute treatment. ${ }^{40-43}$ In these relapse prevention studies, patients were randomized to remain on their SSRI or were switched to placebo, under double-blind conditions. All four studies showed robust effects of the SSRIs in preventing relapse of social phobia (pooled OR $0.25,95 \%$ confidence interval [CI] 0.18-0.35). ${ }^{44}$

\section{Serotonin and norepinephrine reuptake inhibitors}

Venlafaxine is the only serotonin-norepinephrine reuptake inhibitor (SNRI) studied in RCT in patients with social phobia, but improvements in social phobia symptom ratings have also been shown in an open-label trial of the SNRI, duloxetine. ${ }^{45}$ All five reported studies ${ }^{23,28,46-48}$ have shown significantly greater response rates for venlafaxine compared with placebo (Figure 2, OR range for treatment response 1.89-3.78). Four of five studies used flexible dosing, with mean daily doses of approximately $200 \mathrm{mg}$ /day. The single fixed-dose comparison study ${ }^{46}$ showed no differences in outcome measures between $75 \mathrm{mg}$ /day and 150-225 mg/day dose arms, and both separated from placebo. The onset of response across all trials was evident at 4-6 weeks, although maximum separation from placebo continued out to 12 weeks.

\section{Monoamine oxidase inhibitors}

The first placebo-controlled RCT in social phobia assessed phenelzine, an irreversible monoamine oxidase inhibitor. 


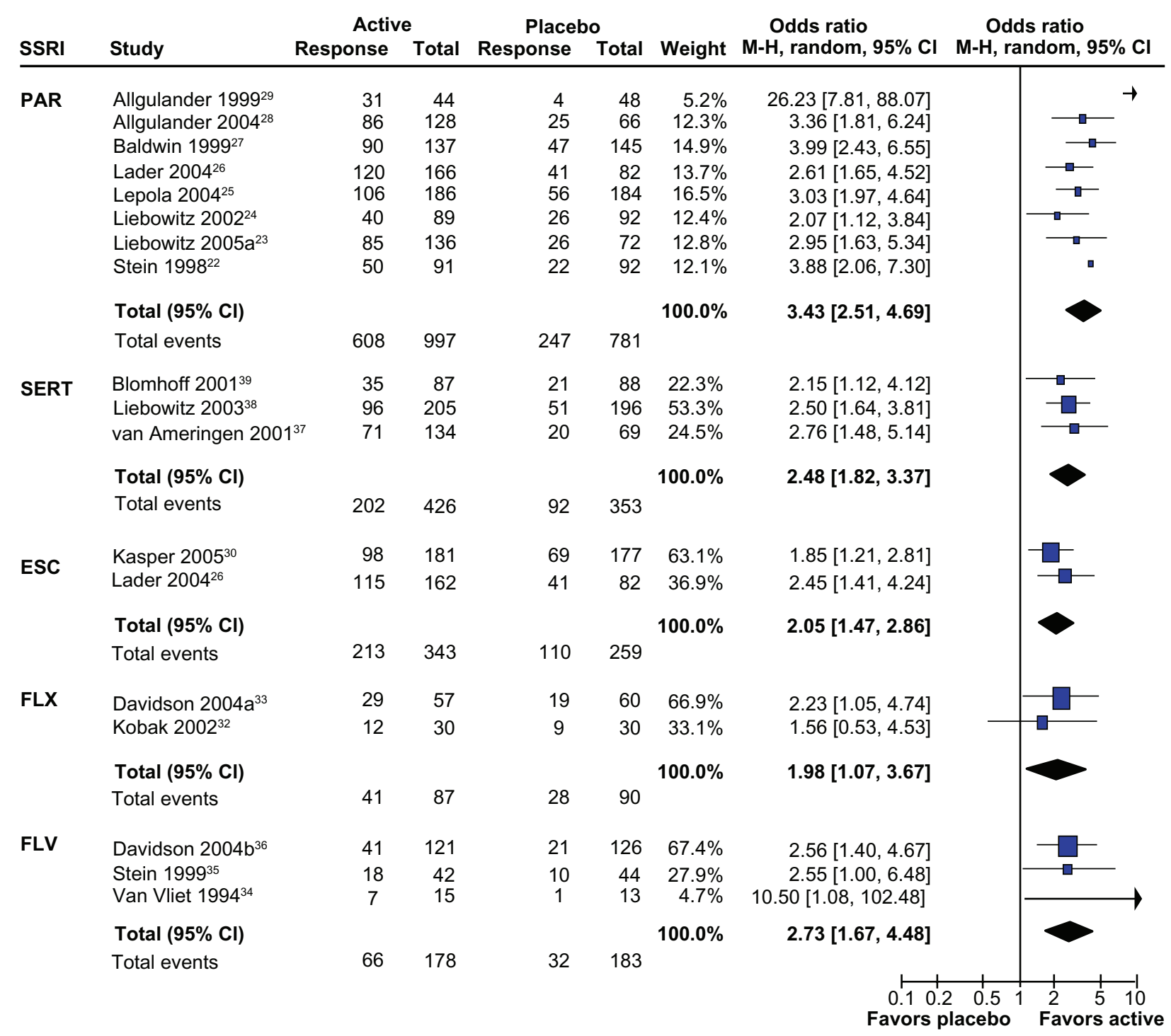

Figure I Odds ratios and $95 \% \mathrm{Cl}$ for treatment response in randomized placebo-controlled trials for SSRI.

Response based on CGI for all studies except for Liebowitz Social Anxiety Scale ${ }^{107}$ in van Vliet et al. ${ }^{34}$ Only the highest ESC dose included for Lader et al. ${ }^{26}$

Abbreviations: $\mathrm{Cl}$, confidence interval; PAR, paroxetine; SERT, sertraline; ESC, escitalopram; FLX, fluoxetine; FLV, fluvoxamine; CGI, Clinical Global Impression; SSRI, selective serotonin reuptake inhibitor; $\mathrm{M}-\mathrm{H}$, Mantel-Haenszel odds ratio.

The rationale for using monoamine oxidase inhibitors was because social phobia and atypical depression share the symptom of increased interpersonal sensitivity, and atypical depression is preferentially responsive to monoamine oxidase inhibitors. ${ }^{49}$ All four studies with this drug ${ }^{50-53}$ showed a significantly greater treatment response compared with placebo; however the pooled OR is heavily influenced by the results from one study ${ }^{50}$ (Figure 3, upper panel). Exclusion of this study ${ }^{50}$ in a sensitivity analysis reduced the pooled OR from 7.22 to 4.58 . There have also been positive open-label studies with tranylcypromine. ${ }^{54}$ Reversible selective inhibitors of monoamine oxidase A were developed with the intention of reducing safety concerns due to drug and food interactions with the original nonselective irreversible monoamine oxidase inhibitors. ${ }^{55}$ RCT have been reported for brofaromine, ${ }^{56-58}$ a drug that was never submitted for regulatory approval, and moclobemide, ${ }^{50,59-63}$ which has been approved in many countries. Excluding brofaromine trials, the pooled OR for response to moclobemide is relatively modest compared with other antidepressant drugs (1.95; 95\% CI 1.37-2.79). High heterogeneity $\left(\mathrm{I}^{2}=69 \%\right)$ was noted in the analysis of this drug class. Exclusion of three studies of reversible selective inhibitors of monoamine oxidase A (two brofaromine, ${ }^{56,58}$ one moclobemide ${ }^{50}$ ) reduced the heterogeneity to $0 \%$, but also reduced the pooled OR from 2.96 to 1.88 .

\section{Other antidepressants}

There are open-label trials in social phobia with the tricyclic antidepressants, imipramine ${ }^{64}$ and clomipramine, ${ }^{65}$ but no RCT. 


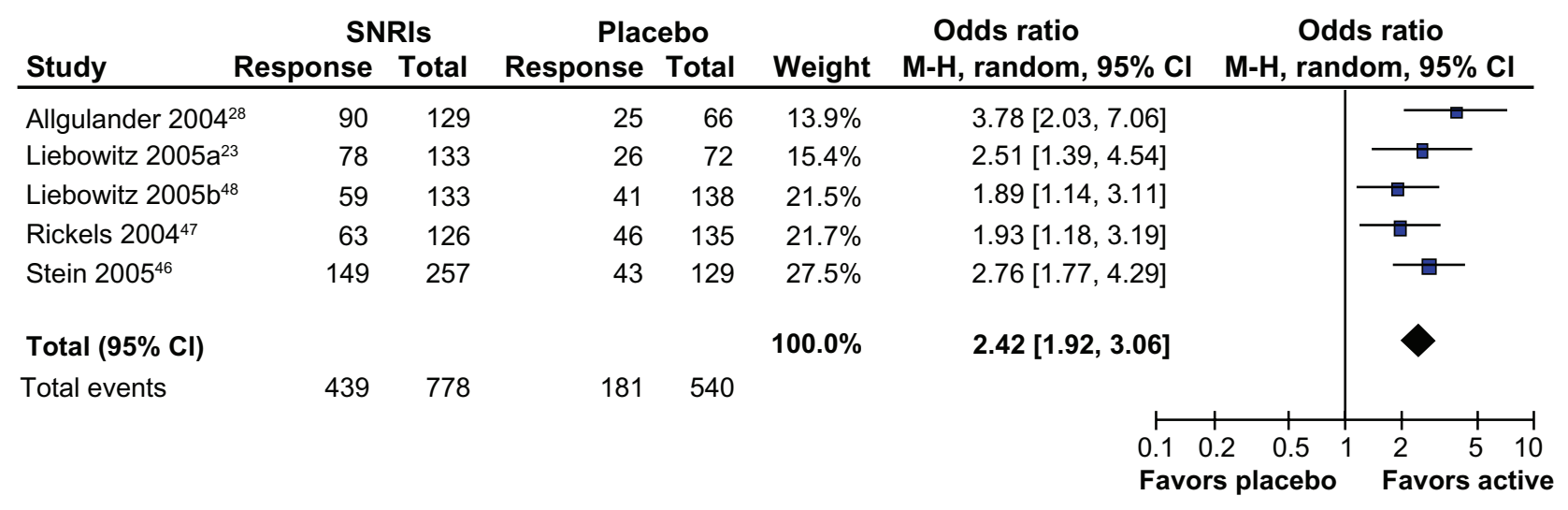

Figure 2 Odds ratios and $95 \% \mathrm{Cl}$ for treatment response in randomized placebo-controlled trials for the serotonin-norepinephrine reuptake inhibitor, venlafaxine. Response based on $\mathrm{CGI}$ for all studies.

Abbreviations: $\mathrm{Cl}$, confidence interval; CGI, Clinical Global Impression; M-H, Mantel-Haenszel odds ratio; SNRIs, selective norepinephrine reuptake inhibitors.

Response to atomoxetine, a selective norepinephrine reuptake inhibitor, was not different from placebo. ${ }^{66}$ Two placebo-controlled RCT in social phobia have been reported for mirtazapine, an antagonist at $5 \mathrm{HT}_{2}, 5 \mathrm{HT}_{3}$, and alpha ${ }_{2}$ adrenoceptors. One study showed a greater reduction in relevant outcome scales compared with placebo, ${ }^{67}$ whereas the other showed no difference. ${ }^{68}$ Both studies were relatively small $(n=30-33$ per treatment arm), and both studies are likely to have been underpowered statistically. Nefazodone, an antagonist at $5 \mathrm{HT}_{1 \mathrm{a}}$ and $5 \mathrm{TH}_{2 \mathrm{a}}$ receptors, did not separate from placebo in a single large clinical trial. ${ }^{69}$ The generally negative findings in social phobia with receptor antagonist antidepressants contrast with the robust positive findings for SSRIs and SNRIs.

\section{Antiepileptic drugs}

The use of antiepileptic drugs in social phobia has been extensively reviewed recently. ${ }^{70}$ Only three antiepileptic drugs have been tested in RCT, and show distinct differences in efficacy. Gabapentin and pregabalin are both ligands at the alpha-2 delta site on voltage-gated calcium channels. Functionally, both drugs reduce the release of a range of excitatory neurotransmitters through binding to this site. ${ }^{71}$

\begin{tabular}{|c|c|c|c|c|c|c|c|c|}
\hline \multirow[b]{2}{*}{ Study } & \multicolumn{2}{|c|}{ MAOIs } & \multicolumn{2}{|c|}{ Placebo } & \multirow[b]{2}{*}{ Weight } & Odds ratio & \multicolumn{2}{|c|}{ Odds ratio } \\
\hline & Response & Total & Response & Total & & $\mathrm{M}-\mathrm{H}$, random, $95 \% \mathrm{Cl}$ & $\mathrm{M}-\mathrm{H}$, rand & om, $95 \% \mathrm{Cl}$ \\
\hline \multicolumn{8}{|l|}{ Irreversible MAOls } & \\
\hline Heimberg $1998^{52}$ & 20 & 31 & 11 & 33 & $31.6 \%$ & $3.64[1.30,10.21]$ & & \\
\hline Liebowitz $1992^{51}$ & 16 & 29 & 6 & 28 & $28.5 \%$ & $4.51[1.41,14.43]$ & & \\
\hline Versiani $1992^{50}$ & 22 & 26 & 4 & 26 & $21.7 \%$ & $30.25[6.71,136.47]$ & & \\
\hline Total $(95 \% \mathrm{Cl})$ & & & & & $100.0 \%$ & $7.22[2.90,17.97]$ & & \\
\hline Total events & 67 & 99 & 24 & 102 & & & & \\
\hline \multicolumn{9}{|l|}{ RIMAs } \\
\hline Fahlen $1995^{58}(\mathrm{~B})$ & 28 & 36 & 9 & 39 & $10.4 \%$ & $11.67[3.95,34.45]$ & & \\
\hline Katschnig $1997^{63}(\mathrm{M})$ & 90 & 193 & 65 & 194 & $17.4 \%$ & $1.73[1.15,2.62]$ & & \\
\hline Lott $1997^{57}(\mathrm{~B})$ & 25 & 50 & 10 & 52 & $12.3 \%$ & $4.20[1.73,10.17]$ & & \\
\hline Noyes $1997^{62}(\mathrm{M})$ & 69 & 84 & 57 & 85 & $14.1 \%$ & $2.26[1.10,4.64]$ & & \\
\hline Oosterbaan $2001^{61}(\mathrm{M})$ & 7 & 27 & 6 & 27 & $8.9 \%$ & $1.23[0.35,4.28]$ & & 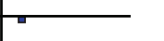 \\
\hline Schneier $1998^{60}(\mathrm{M})$ & 69 & 40 & 5 & 37 & $9.0 \%$ & $1.36[0.39,4.72]$ & & $\square$ \\
\hline Stein $2002^{59}(\mathrm{M})$ & 81 & 188 & 57 & 189 & $17.2 \%$ & $1.75[1.15,2.68]$ & & \\
\hline van Vliet $1992^{56}(B)$ & 11 & 15 & 0 & 14 & $2.5 \%$ & $74.11[3.61,1522.44]$ & & \\
\hline Versiani $1992^{50}(\mathrm{M})$ & 17 & 26 & 4 & 26 & $8.3 \%$ & $10.39[2.73,39.56]$ & & \\
\hline Total $(95 \% \mathrm{Cl})$ & & 659 & & 663 & $100.0 \%$ & $2.96[1.78,4.91]$ & & \\
\hline \multirow[t]{2}{*}{ Total events } & 335 & & 213 & & & & & \\
\hline & & & & & & $\begin{array}{c}0.1 \\
\text { Favor }\end{array}$ & $\begin{array}{lr}2 & 0.5 \\
\text { placebo }\end{array}$ & $\begin{array}{c}2 \\
\text { Favors }\end{array}$ \\
\hline
\end{tabular}

Figure 3 Odds ratios and $95 \% \mathrm{Cl}$ for treatment response in randomized placebo-controlled trials for irreversible and reversible MAOls.

Response based on CGI for all studies except social phobia subscale of the Fear Questionnaire ${ }^{108}$ for Gelernter et al, ${ }^{53}$ and the Hamilton Anxiety Scale ${ }^{109}$ for van Vliet et al. ${ }^{56}$ Abbreviations: B, brofaromine; M, moclobemide; MAOls, monoamine oxidase inhibitors; $\mathrm{Cl}$, confidence interval; $\mathrm{M}-\mathrm{H}$, Mantel-Haenszel odds ratio. 
There are three positive RCT with alpha-2 delta ligands ${ }^{72-74}$ (see Figure 4). The onset of anxiolytic effects is relatively rapid, occurring within the first week of treatment. The anxiolytic dose-response has only been formally assessed for pregabalin, and efficacy is only evident at the maximum dose (600 mg/day), but not at lower doses. ${ }^{73,74}$ This is in contrast with the effect of pregabalin in, eg, generalized anxiety disorder, where the anxiolytic dose-response is seen at much lower doses ( $150 \mathrm{mg} /$ day) ${ }^{75}$ There are no long-term treatment or relapse prevention data for alpha-2 delta ligands.

The only other antiepileptic drug assessed in RCT is levetiracetam, which has a complex pharmacology. ${ }^{70} \mathrm{~A}$ large trial against placebo was negative. ${ }^{76}$ The dose achieved in this trial (1180 mg/day) was at the low end of the dose range for epilepsy (1000-3000 mg/day). However, an earlier small RCT, in which higher levetiracetam doses were achieved, was also negative. ${ }^{31}$

Open-label trials of valproate, ${ }^{77}$ topiramate, ${ }^{78}$ and tiagabine ${ }^{79}$ have also been reported, all of which showed reductions in relevant social phobia rating scales. All studies were small (involving 17-54 subjects), and the magnitude of the change in symptom ratings was within the range that has been reported for placebo arms in other RCT.

\section{Benzodiazepines}

In clinical practice, there appears to be widespread use of benzodiazepines alone or in combination with antidepressants for social phobia, ${ }^{80,81}$ but clinical evidence to support this use is relatively limited. There are three placebo-controlled RCT, one each for clonazepam, ${ }^{82}$ bromazepam,${ }^{83}$ and alprazolam.${ }^{53}$ All studies showed significantly greater improvement on a range of clinician-rating and self-rating scales compared with placebo. The mean doses used in these studies were generally modest (clonazepam $2.4 \mathrm{mg} /$ day, bromazepam $21 \mathrm{mg} /$ day, alprazolam $4.2 \mathrm{mg} /$ day). The time course of response was only reported for the clonazepam study. Although there was a higher proportion of responders after one week of treatment (clonazepam 13.5\%, placebo 0\%), maximal response rates were noted after 6 weeks of treatment. Continuation of clonazepam treatment in treatment responders has been shown to decrease rates of relapse in social phobia compared with those switched to placebo. ${ }^{84}$

Although the clinical practice of combining antidepressants and benzodiazepines appears to be common, it has been studied in only one small RCT. Combined paroxetine and clonazepam had a higher response rate (albeit not a statistically significant one) in an RCT in social phobia (79\% versus $43 \%, P=0.06$ ) compared with paroxetine plus placebo. ${ }^{85}$

\section{Antipsychotics}

Increased use of second-generation antipsychotic drugs for anxiety disorders has been identified in US prescribing data between 1996 and 2007..$^{86}$ The evidence base to support use in social phobia is very limited, with two small RCT. CGI response rates were not statistically significantly different between placebo and olanzapine ${ }^{87}$ or quetiapine, ${ }^{88}$ although the very small subject numbers $(n=7-10$ subjects on active medication) suggest that neither trial was adequately powered statistically.

\section{Other agents}

Negative RCT outcomes have been reported for buspirone, a serotonin $1 \mathrm{~A}$ partial agonist, ${ }^{89}$ and for atenolol, a betaadrenoceptor antagonist. ${ }^{89}$

\section{Summary of medication response}

Placebo-controlled RCT have been reported for seven drug classes in social phobia. Figure 5 shows the comparative OR

\begin{tabular}{|c|c|c|c|c|c|c|c|c|}
\hline \multirow[b]{2}{*}{ Study } & \multicolumn{2}{|c|}{ A2Ds } & \multicolumn{2}{|c|}{ Placebo } & \multirow[b]{2}{*}{ Weight } & Odds ratio & \multirow{2}{*}{\multicolumn{2}{|c|}{$\begin{array}{l}\text { Odds ratio } \\
\mathrm{M}-\mathrm{H} \text {, random, } 95 \% \mathrm{Cl}\end{array}$}} \\
\hline & Response & Total & Response & Total & & $\mathrm{M}-\mathrm{H}$, random, $95 \% \mathrm{Cl}$ & & \\
\hline Feltner $2011^{74} \mathrm{P}$ & 43 & 82 & 20 & 82 & $52.9 \%$ & $3.42[1.76,6.64]$ & & - \\
\hline Pande $1999^{72} \mathrm{G}$ & 13 & 34 & 6 & 35 & $18.7 \%$ & $2.99[0.98,9.16]$ & & \\
\hline Pande $2004^{73} \mathrm{P}$ & 20 & 47 & 10 & 46 & $28.4 \%$ & $2.67[1.08,6.61]$ & & \\
\hline Total $(95 \% \mathrm{Cl})$ & & & & & $100.0 \%$ & $3.11[1.92,5.04]$ & & \\
\hline Total events & 76 & 163 & 36 & 163 & & & & \\
\hline & & & & & & 0.10. & $\begin{array}{ll}2 & 0.5\end{array}$ & $\begin{array}{ll}7 & 10\end{array}$ \\
\hline & & & & & & Favors & olacebo & Favors active \\
\hline
\end{tabular}

Figure 4 Odds ratios and $95 \% \mathrm{Cl}$ for treatment response in randomized placebo-controlled trials for the $A 2 \mathrm{D}$ ligands pregabalin $(\mathrm{P})$ and gabapentin $(\mathrm{G})$. Response based on CGI for all studies. Only the highest pregabalin doses are reported for Pande et a ${ }^{73}$ and Feltner et al. ${ }^{74}$ Abbreviations: A2D, alpha-2-delta; $\mathrm{Cl}$, confidence interval; $\mathrm{M}-\mathrm{H}$, Mantel-Haenszel odds ratio. 


\begin{tabular}{|c|c|c|c|c|c|c|c|}
\hline \multirow[b]{2}{*}{ Drug class } & \multicolumn{2}{|c|}{ Active } & \multicolumn{2}{|c|}{ Placebo } & \multirow{2}{*}{$\begin{array}{l}\text { Odds ratio } \\
\mathrm{M}-\mathrm{H} \text {, random, } 95 \% \mathrm{Cl}\end{array}$} & \multirow{2}{*}{\multicolumn{2}{|c|}{$\begin{array}{l}\text { Odds ratio } \\
\mathrm{M}-\mathrm{H} \text {, random, } 95 \% \mathrm{Cl}\end{array}$}} \\
\hline & Response & Total & Response & Total & & & \\
\hline All SSRIs & 1130 & 2011 & 509 & 1666 & $2.78[2.32,3.32]$ & & \\
\hline SNRIs & 439 & 778 & 181 & 540 & $2.42[1.92,3.06]$ & & \\
\hline MAOIs (irrev) & 67 & 99 & 24 & 102 & $7.22[2.90,17.97]$ & & \\
\hline MAOIs (RIMA) & 368 & 851 & 232 & 857 & $2.96[1.78,4.91]$ & & \\
\hline A2Ds & 76 & 163 & 36 & 163 & $3.11[1.92,5.04]$ & & \\
\hline
\end{tabular}

Figure 5 Odds ratios and $95 \% \mathrm{Cl}$ for treatment response in randomized placebo-controlled trials for five drug classes.

Abbreviations: $\mathrm{Cl}$, confidence interval; SSRIs, selective serotonin reuptake inhibitors; SNRIs, serotonin-norepinephrine reuptake inhibitors; MAOIs, monoamine oxidase inhibitors; irrev, irreversible; RIMA, selective inhibitors of monoamine oxidase A; M-H, Mantel-Haenszel odds ratio.

for treatment response for pooled results from five of these classes (insufficient data were available to include antipsychotic and benzodiazepine class data). The greatest treatment response was for the irreversible nonselective monoamine oxidase inhibitor, phenelzine. It should be noted that this estimate is heavily influenced by data from one study, ${ }^{50}$ and that relatively few patients were included in the four studies. Because of the risk of food and drug interactions, use of this class of drugs would not be first-line. The OR for reversible selective inhibitors of monoamine oxidase $\mathrm{A}$ is influenced by brofaromine data; brofaromine is not available to prescribe, and responses for moclobemide alone are more modest (OR 1.95; 95\% CI 1.37-2.79). The other three drug classes have similar OR for treatment response, suggesting that differences in safety and tolerability profiles might influence selection between drug classes. Efficacy of the alpha- 2 delta ligand, pregabalin, has only been reported at the $600 \mathrm{mg}$ dose but not at lower doses; this higher dose is associated with high rates of dizziness and sedation. By default, this leaves SSRIs and the SNRI, venlafaxine, as first-line medication options for treatment of social phobia.

\section{Psychological treatment trials}

Over 30 randomized trials of psychological treatments have been conducted. ${ }^{15,16}$ Collectively these indicate that psychological interventions are effective in the treatment of social phobia. A critical issue is, however, effective relative to what? There is great variability in the nature of the control arm in psychological trials. These may include waitlist control, psychological placebo, drug, drug-placebo, or treatment as usual (which may or may not include drugs). Most studies have used wait-list control which is the least stringent test of effectiveness. Recent meta-analyses of psy- chological treatments have found fairly large effect sizes for psychological treatments compared with wait-list controls (Cohen's $d$ of 0.86), but smaller effect sizes (0.36-0.38) compared with placebo or treatment as usual. ${ }^{15,16}$

In addition to the question of whether psychological treatments are effective, a second question is which psychological treatment is optimal. Most studies, especially the earlier ones, have investigated variants or components of cognitive behavior therapy (CBT). The two meta-analyses cited earlier ${ }^{15,16}$ conducted subgroup analyses to determine whether inclusion of specific components of CBT, such as exposure, cognitive restructuring, relaxation, and social skills training makes a difference to treatment effectiveness. Neither study found significant differences in effectiveness as a function of inclusion versus noninclusion of any of these treatment components, nor did they find differences according to whether treatment was delivered individually or in group format.

This might suggest that it does not matter which type of psychological treatment is used, but recent trials of CBT against other evidence-based psychological treatments suggest otherwise. Koszycki et $\mathrm{al}^{90}$ randomized participants with DSM-IV diagnoses of generalized social phobia to either group CBT or mindfulness-based stress reduction. Both groups improved, but the improvement with CBT was significantly greater. Borge et $\mathrm{al}^{91}$ compared interpersonal therapy with $\mathrm{CBT}$ in a randomized trial conducted in a residential setting. Both treatments were equally effective, although the researchers noted that the CBT intervention was associated with less improvement compared with that reported by prior researchers. In a recent randomized controlled trial, Stangier et a ${ }^{92}$ compared cognitive therapy with interpersonal psychotherapy. Both treatments were superior 
to wait-list control, but cognitive therapy was significantly more effective, a difference that was maintained at one-year follow-up. On the basis of this small number of studies, CBT or some variant of it remains the psychological treatment of choice, but interpersonal therapy or mindfulness-based therapies may be useful alternatives for patients who do not respond to CBT. A further important consideration is whether treatment effects endure. A meta-analysis of nine RCT of variants of CBT found significant effects at post-treatment (Cohen's $d$ of 0.68 across all trials) that were maintained at follow-up, with no drop in effect size $(0.76){ }^{16}$

The availability of psychological treatments such as CBT is often limited by funding or therapist constraints, so recent RCT that have found Internet CBT to be equally effective as the therapist-delivered version are a promising development. ${ }^{93,94}$ More research is required to determine whether Internet therapy can be as effective as the therapistdelivered version for the full spectrum of social phobia severity and complexity (in terms of comorbidity).

\section{Medication versus psychological treatment}

There are relatively few trials incorporating direct comparisons of medication with psychological treatments in social phobia. On the basis of the two trials shown in Figure 6, there are no significant differences in effectiveness between SSRIs and psychological treatments. One additional trial of cognitive therapy versus fluoxetine, ${ }^{95}$ which could not be included in the meta-analysis because the outcome analysis did not include responder data, found a significantly greater effectiveness of cognitive therapy. The meta-analysis of four monoamine oxidase inhibitor trials (Figure 6) suggests that these drugs may be superior to psychological treatments, but this result is not statistically significant.

It is also important to consider how these treatments compare over the longer term. Three studies ${ }^{95-97}$ have published follow-up data on outcomes after a treatment-free period. In all three trials, the psychological treatment showed greater maintenance of treatment gains or protection against relapse relative to the drug treatments.

\section{Medication versus combined medication- psychological treatment trials}

There are five studies that have assessed treatment response in direct comparisons of medication with combined medicationpsychological treatments in social phobia (two SSRI studies, ${ }^{33,39}$ two monoamine oxidase inhibitor studies,,${ }^{98,99}$ and one benzodiazepine study ${ }^{100}$ Figure 7). For response rates in the SSRI and monoamine oxidase inhibitor studies, there were nonsignificant trends in favor of combined medication-psychological treatments over medication alone. For the single benzodiazepine study, there was a statistically significant advantage in favor of combined treatment (Figure 7). It should be noted that all studies were relatively small in size and thus may not have been adequately powered statistically.

\begin{tabular}{|c|c|c|c|c|c|c|c|}
\hline \multirow[b]{2}{*}{ Study } & \multicolumn{2}{|c|}{ Drug } & \multicolumn{2}{|c|}{ Psychotherapy } & \multirow[b]{2}{*}{ Weight } & Odds ratio & \multirow{2}{*}{$\begin{array}{c}\text { Odds ratio } \\
\mathrm{M}-\mathrm{H} \text {, random, } 95 \% \mathrm{Cl}\end{array}$} \\
\hline & Response & Total & Response & Total & & $\mathrm{M}-\mathrm{H}$, random, $95 \% \mathrm{Cl}$ & \\
\hline $\begin{array}{l}\text { SSRIs } \\
\text { Blomhoff } 2001^{39}\end{array}$ & 35 & 87 & 30 & 91 & $51.6 \%$ & $1.37[0.74,2.25]$ & \\
\hline Davidson $2004 a^{33}$ & 29 & 57 & 60 & 119 & $48.4 \%$ & $1.02[0.54,1.92]$ & \\
\hline $\begin{array}{l}\text { Total }(95 \% \mathrm{Cl}) \\
\text { Total events }\end{array}$ & 64 & 144 & 90 & 210 & $100.0 \%$ & $1.19[0.76,1.84]$ & \\
\hline $\begin{array}{l}\text { MAOls } \\
\text { Blanco } 2010^{98}\end{array}$ & 19 & 35 & 16 & 34 & $36.7 \%$ & $1.34[0.52,3.44]$ & \\
\hline Gelernter $1991^{53}$ & 9 & 13 & 4 & 17 & $15.5 \%$ & $7.31[1.44,37.16]$ & \\
\hline Heimberg $1998^{52}$ & 20 & 31 & 21 & 36 & $34.4 \%$ & $1.30[0.48,3.50]$ & \\
\hline Prasko $2006^{99}$ & 18 & 20 & 19 & 24 & $13.5 \%$ & $2.37[0.41,13.79]$ & 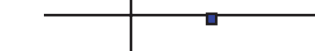 \\
\hline $\begin{array}{l}\text { Total }(95 \% \mathrm{Cl}) \\
\text { Total events }\end{array}$ & 66 & 99 & 60 & 111 & $100.0 \%$ & $1.86[0.94,3.69]$ & \\
\hline & & & & & & Favors psy & $\begin{array}{ccc}0.5 & 1 & 2\end{array}$ \\
\hline
\end{tabular}

Figure 6 Odds ratios and $95 \% \mathrm{Cl}$ for treatment response in randomized placebo-controlled trials for drug versus psychotherapy comparisons.

Blomhoff et $\mathrm{a}^{39}$ used exposure therapy; all other trials used cognitive behavioral therapy as the psychotherapy intervention. Response based on Clinical Global Impression for all studies except social phobia subscale of the Fear Questionnaire ${ }^{108}$ for Gelernter et al, ${ }^{53}$ and the Social Anxiety Scale ${ }^{107}$ for Heimberg et al. ${ }^{52}$

Abbreviations: $\mathrm{Cl}$, confidence interval; SSRIs, selective serotonin reuptake inhibitors; MAOls, monoamine oxidase inhibitors; $\mathrm{M}-\mathrm{H}$, Mantel-Haenszel odds ratio. 


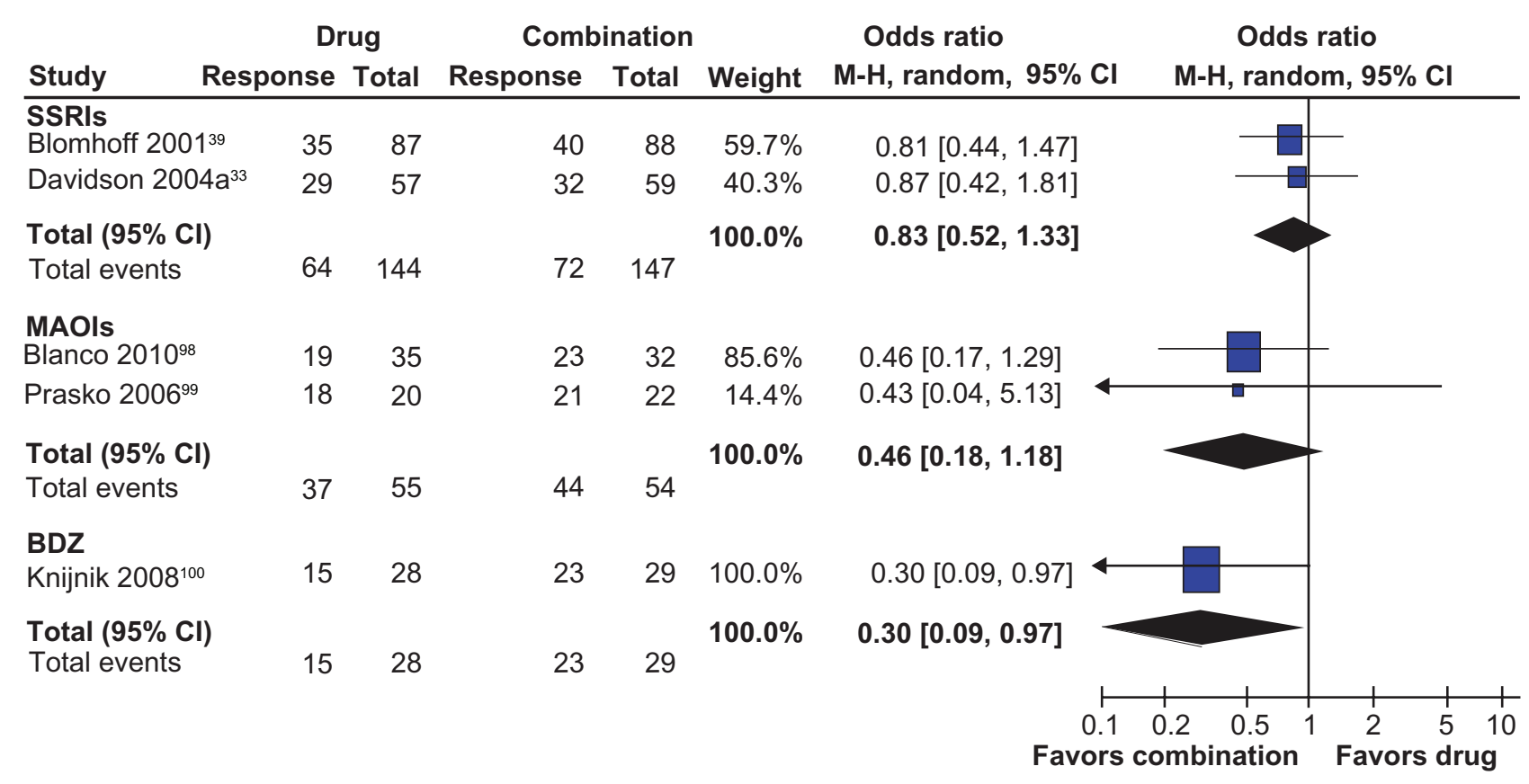

Figure 7 Odds ratios and $95 \% \mathrm{Cl}$ for treatment response in randomized placebo-controlled trials for medication compared with combined medication-psychological treatment. Blomhoff et a $\left.\right|^{39}$ used exposure therapy; Knijnik et al ${ }^{100}$ used psychodynamic group therapy; all other trials used cognitive behavioral therapy as the psychotherapy intervention. Response based on Clinical Global Impression for all studies.

Abbreviations: $\mathrm{Cl}$, confidence interval; SSRIs, selective serotonin reuptake inhibitors; MAOls, monoamine oxidase inhibitors; BDZ, benzodiazepines; M-H, Mantel-Haenszel odds ratio.

\section{Psychological versus combined medication-psychological treatment trials}

There are four studies that have assessed treatment response in direct comparisons of psychological treatment with combined medication-psychological treatments in social phobia (two SSRI studies, ${ }^{33,39}$ two monoamine oxidase inhibitor studies ${ }^{98,99}$ Figure 8). For the pooled response rate in the SSRI studies, there was a nonsignificant trend in favor of combined medication-psychological treatments over psychological treatment alone. For the pooled response rate in the monoamine oxidase inhibitor studies, there was a significant trend in favour of combined medicationpsychological treatments over psychological treatment alone (Figure 8). It should be noted that all studies were relatively small in size and thus may not have been adequately powered statistically.

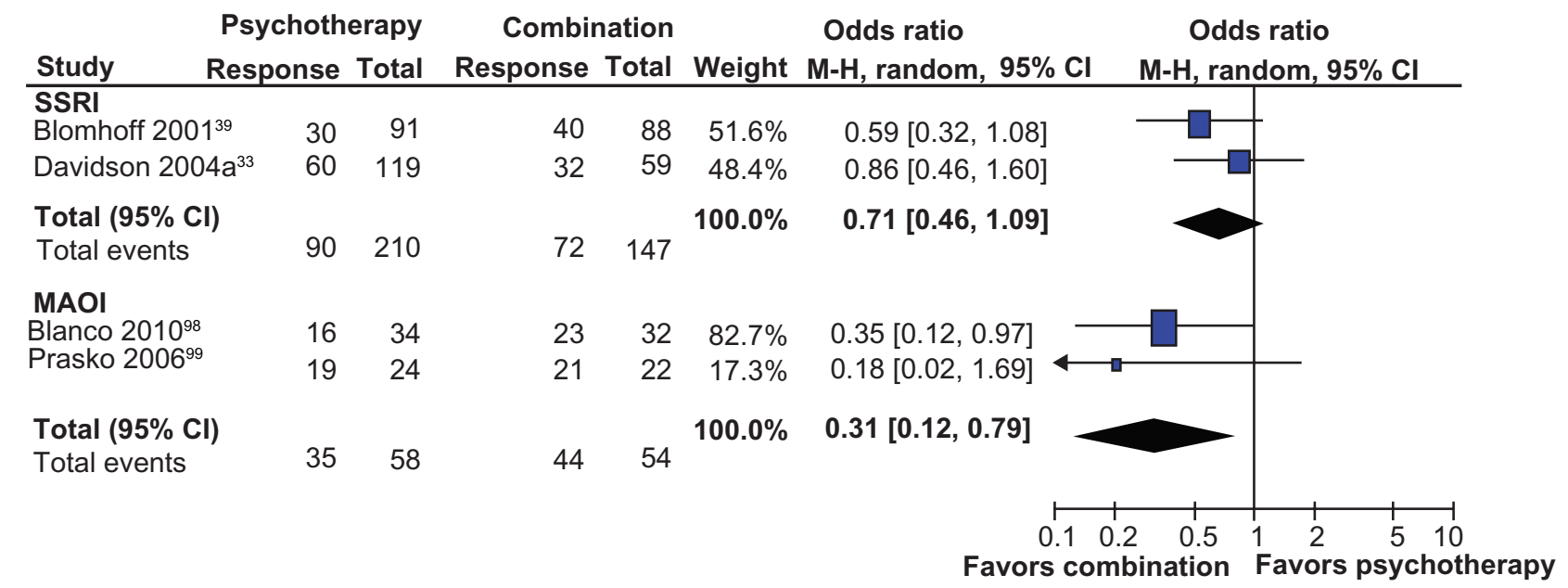

Figure 8 Odds ratios and $95 \% \mathrm{Cl}$ for treatment response in randomized placebo-controlled trials for psychological therapy compared with combined medication-psychological treatment. Blomhoff et $\mathrm{al}^{39}$ used exposure therapy; all other trials used cognitive behavioral therapy as the psychotherapy intervention. Response based on Clinical Global Impression for all studies.

Abbreviations: $\mathrm{Cl}$, confidence interval; SSRI, selective serotonin reuptake inhibitor; MAOI, monoamine oxidase inhibitor; M-H, Mantel-Haenszel odds ratio. 


\section{Discussion}

All social phobia treatment guidelines recommend some combination of medication and psychological treatment for optimal management of patients with social phobia. ${ }^{17,18}$ Our meta-analysis findings are not inconsistent with this, although significant advantages of combination therapies are only evident with some drug classes and from a fairly small number of studies. For medications, the best initial choices would be SNRIs and SSRIs. For patients who do not respond to adequate doses/durations of dosing of either of these drug classes, monoamine oxidase inhibitors would be a relevant second-line choice. The older nonselective irreversible monoamine oxidase inhibitor, phenelzine, is clearly more effective than the newer reversible selective agent, moclobemide, although its use is constrained by its well known food and drug interaction liabilities and side effect profile at higher doses. A number of other drug classes are commonly used for symptom relief in social phobia, and appear to be effective, although clinical trial data are limited. Benzodiazepine use should be limited to brief courses because of their dependence liability, relatively high levels of cognitive toxicity, ${ }^{102}$ and potential for interfering with psychological treatment. ${ }^{103}$ Low doses of quetiapine are also commonly used for anxiolysis, ${ }^{104,105}$ but the one RCT for this drug in social phobia was clearly underpowered to assess its effect. ${ }^{88}$ Given that all benzodiazepines and most antipsychotic drugs have now become genericized, there is no commercial rationale for additional RCT in this area, and therefore it is unlikely that additional data will be generated to clarify how best to use these drugs in social phobia. The alpha-2-delta ligand, pregabalin, appears to have anxiolytic response rates comparable with SSRIs and SNRIs, but at doses of $600 \mathrm{mg} /$ day where sedation and other side effects are likely to be reported, so its use should be reserved for refractory patients at this time. Combination drug treatment appears to be commonly used, ${ }^{80,81}$ but is not supported by RCT. The issue of how to treat patients who fail to respond to initial treatment is unresolved. A recent clinical guidance suggests a switching strategy, presumably based on data from the STAR*D studies, ${ }^{106}$ but this is not supported by clinical trial data.

Of the psychotherapeutic approaches, CBT or some variant of it appears to be the most effective psychological treatment. It has the largest evidence base, and thus far it has emerged as superior in head-to-head comparisons with other recently developed, evidence-based treatments of mental disorders. CBT also appears to offer better protection from relapse at termination of treatment relative to drug treatments.

\section{Limitations}

Most treatment trials, particularly medication trials, only enroll a highly selected group of patients. Patients with comorbid disorders, such as current depression, alcohol misuse disorders, or suicidal ideation are usually excluded. As noted in the Introduction, comorbidity is the rule rather than the exception for patients with social phobia. Moreover, social phobia has a high degree of overlap with agoraphobia, ${ }^{101}$ and can be accompanied by fears of public transport, meaning that some of the most severely affected will not seek treatment. This has implications for the generalizability of the findings reported here.

The effectiveness of combined treatments for social phobia highlights the problem that psychological treatments are not widely available in most countries, and social phobia is one of the most prevalent mental disorders, suggesting significant unmet need for the optimal treatment package for this debilitating disorder. This makes the emerging evidence of the efficacy of Internet-based CBT,,${ }^{94}$ at least for uncomplicated presentations, a potentially important new opportunity to maximize the availability of combined treatments.

\section{Disclosure}

Within the last 3 years, JC has received a speaker's honorarium from Novartis Pharmaceuticals, and PG has been on the scientific advisory boards for Forrest Pharmaceuticals, Demerx Pharmaceuticals, and Janssen-Cilag.

\section{References}

1. American Psychiatric Association. Diagnostic and Statistical Manual of Mental Health Disorders, 4th ed. Washington DC: American Psychiatric Association; 2000.

2. American Psychiatric Association. Diagnostic and Statistical Manual of Mental Health Disorders, 3rd ed. Washington, DC: American Psychiatric Association; 1980.

3. Magee WJ, Eaton WW, Wittchen H-U, McGonagle KA, Kessler RC. Agoraphobia, simple phobia, and social phobia in the National Comorbidity Survey. Arch Gen Psychiatry. 1996;53(2):159-168.

4. Ruscio A, Brown T, Chiu W, Sareen J, Stein M, Kessler R. Social fears and social phobia in the USA: results from the National Comorbidity Survey Replication. Psychol Med. 2008;38(1):15-28.

5. Stein MB, Kean YM. Disability and quality of life in social phobia: epidemiologic findings. Am J Psychiatry. 2000;157(10):1606-1613.

6. Katzelnick DJ, Kobak KA, DeLeire T, et al. Impact of generalized social anxiety disorder in managed care. Am J Psychiatry. 2001; 158(12):1999-2007.

7. Davidson JR, Hughes D, George LK, Blazer DG. The epidemiology of social phobia: findings from the Duke Epidemiological Catchment Area Study. Psychol Med. 1993;23(3):709-718.

8. DeWit DJ, Ogborne A, Offord D, MacDonald K. Antecedents of the risk of recovery from DSM-III-R social phobia. Psychol Med. 1999;29(3):569-582

9. Chartier MJ, Hazen AL, Stein MB. Lifetime patterns of social phobia: a retrospective study of the course of social phobia in a nonclinical population. Depress Anxiety. 1998;7(3):113-121. 
10. Schneier FR, Johnson J, Hornig CD, Liebowitz MR, Weissman MM. Social phobia: comorbidity and morbidity in an epidemiologic sample. Arch Gen Psychiatry. 1992;49(4):282-288.

11. Schneier FR, Foose TE, Hasin DS, et al. Social anxiety disorder and alcohol use disorder co-morbidity in the National Epidemiologic Survey on Alcohol and Related Conditions. Psychol Med. 2010;40(6):977-988.

12. Kessler RC, Ustun TB, editors. The WHO World Mental Health Surveys: Global Perspectives on the Epidemiology of Mental Disorders. New York, NY: Cambridge University Press; 2008.

13. Schneier FR. Pharmacotherapy of social anxiety disorder. Expert Opin Pharmacother. 2011;12(4):615-625.

14. Ravindran LN, Stein MB. The pharmacologic treatment of anxiety disorders: a review of progress. J Clin Psychiatry. 2010;71(7): 839-854.

15. Acarturk C, Cuijpers P, van Straten A, de Graaf R. Psychological treatment of social anxiety disorder: a meta-analysis. Psychol Med. 2009;39(2):241-254.

16. Powers MB, Sigmarsson S, Emmelkamp PMG. A meta-analytic review of psychological treatments for social anxiety disorder. Int J Cogn Ther 2008;1(2):94-113.

17. Ganasen K, Ipser J, Stein D. Augmentation of cognitive behavioral therapy with pharmacotherapy. Psychiatr Clin North Am. 2010;33(3): 687-699.

18. Stein DJ, Baldwin DS, Bandelow B, et al. A 2010 evidence-based algorithm for the pharmacotherapy of social anxiety disorder. Curr Psychiatry Rep. 2010;12(5):471-477.

19. Guy W. ECDEU Assessment Manual for Psychopharmacology Revised. Rockville, MD: National Institute of Mental Health; 1976.

20. Bandelow B, Seidler-Brandler U, Becker A, Wedekind D, Rüther E. Meta-analysis of randomized controlled comparisons of psychopharmacological and psychological treatments for anxiety disorders. World J Biol Psychiatry. 2007;8(3):175-187.

21. Stein DJ, Ipser J, van Balkom AJ. Pharmacotherapy for social anxiety disorder. Cochrane Database Syst Rev. 2000;4.

22. Stein MB, Liebowitz MR, Lydiard RB, Pitts CD, Bushnell W, Gergel I. Paroxetine treatment of generalized social phobia (social anxiety disorder): a randomized controlled trial. JAMA. 1998;280(8): 708-713.

23. Liebowitz MR, Gelenberg AJ, Munjack D. Venlafaxine extended release vs placebo and paroxetine in social anxiety disorder. Arch Gen Psychiatry. 2005a;62(2):190-198.

24. Liebowitz MR, Stein MB, Tancer M, Carpenter D, Oakes R, Pitts CD. A randomized, double-blind, fixed-dose comparison of paroxetine and placebo in treatment of generalized social anxiety disorder. $J$ Clin Psychiatry. 2002;63(1):66-74.

25. Lepola U, Bergtholdt B, St Lambert J, Davy KL, Ruggiero L. Controlled-release paroxetine in the treatment of patients with social anxiety disorder. J Clin Psychiatry. 2004;65(2):222-229.

26. Lader M, Stender K, Bürger V, Nil R. Efficacy and tolerability of escitalopram in 12- and 24-week treatment of social anxiety disorder: Randomised, double-blind, placebo-controlled, fixed-dose study. Depress Anxiety. 2004;19(4):241-248.

27. Baldwin D, Bobes J, Stein DJ, Scharwachter I, Faure M. Paroxetine in social phobia/social anxiety disorder. Randomised, double-blind, placebo-controlled study. Paroxetine Study Group. $\mathrm{Br} J$ Psychiatry. 1999;175(2):120-126.

28. Allgulander C, Mangano R, Zhang J, et al. Efficacy of venlafaxine ER in patients with social anxiety disorder: a double-blind, placebo-controlled, parallel-group comparison with paroxetine. Hum Psychopharmacol. 2004;19(6):387-396.

29. Allgulander C. Paroxetine in social anxiety disorder: a randomized placebo-controlled study. Acta Psychiatr Scand. 1999;100(3):193-198.

30. Kasper S, Stein DJ, Loft H, Nil R. Escitalopram in the treatment of social anxiety disorder. Br J Psychiatry. 2005;186(3):222-226.

31. Zhang W, Connor KM, Davidson JRT. Levetiracetam in social phobia: a placebo controlled pilot study. J Psychopharmacol. 2005;19(5):551-553.
32. Kobak KA, Greist JH, Jefferson JW, Katzelnick DJ. Fluoxetine in social phobia: a double-blind, placebo-controlled pilot study. J Clin Psychopharmacol. 2002;22(3):257-262.

33. Davidson JRT, Foa EB, Huppert JD, et al. Fluoxetine, comprehensive cognitive behavioral therapy, and placebo in generalized social phobia. Arch Gen Psychiatry. 2004a;61(10):1005-1013.

34. van Vliet I, Boer J, Westenberg H. Psychopharmacological treatment of social phobia; a double blind placebo controlled study with fluvoxamine. Psychopharmacology. 1994;115(1):128-134.

35. Stein MB, Fyer AJ, Davidson JR, Pollack MH, Wiita B. Fluvoxamine treatment of social phobia (social anxiety disorder): a double-blind, placebo-controlled study. Am J Psychiatry. 1999;156(5):756-760.

36. Davidson J, Yaryura-Tobias J, DuPont R, et al. Fluvoxamine-controlled release formulation for the treatment of generalized social anxiety disorder. J Clin Psychopharmacol. 2004b;24(2):118-125.

37. Van Ameringen MA, Lane RM, Walker JR, et al. Sertraline treatment of generalized social phobia: a 20-week, double-blind, placebo-controlled study. Am J Psychiatry. 2001;158(2):275-281.

38. Liebowitz MR, DeMartinis NA, Weihs K, et al. Efficacy of sertraline in severe generalized social anxiety disorder: results of a double-blind, placebo-controlled study. J Clin Psychiatry. 2003;64(7):785-792.

39. Blomhoff S, Haug TT, Hellstrom K, et al. Randomised controlled general practice trial of sertraline, exposure therapy and combined treatment in generalised social phobia. Br J Psychiatry. 2001;179(1):23-30.

40. Montgomery SA, Nil R, Durr-Pal N, Loft H, Boulenger JP. A 24-week randomized, double-blind, placebo-controlled study of escitalopram for the prevention of generalized social anxiety disorder. J Clin Psychiatry. 2005;66(10):1270-1278.

41. Stein MB, Chartier MJ, Hazen AL, et al. Paroxetine in the treatment of generalized social phobia: open-label treatment and doubleblind placebo-controlled discontinuation. J Clin Psychopharmacol. 1996;16(3):218-222.

42. Stein DJ, Versiani M, Hair T, Kumar R. Efficacy of paroxetine for relapse prevention in social anxiety disorder: a 24-week study. Arch Gen Psychiatry. 2002;59(12):1111-1118.

43. Walker JR, Van Ameringen MA, Swinson R, et al. Prevention of relapse in generalized social phobia: results of a 24-week study in responders to 20 weeks of sertraline treatment. JClin Psychopharmacol. 2000;20(6):636-644.

44. Donovan MR, Glue P, Kolluri S, Emir B. Comparative efficacy of antidepressants in preventing relapse in anxiety disorders - a metaanalysis. J Affective Dis. 2010;123(1):9-16.

45. Simon NM, Worthington JJ, Moshier SJ, et al. Generalized social anxiety disorder: a preliminary randomized trial of increased dose to optimize response. CNS Spectr. 2010;15(7):436-443.

46. Stein MB, Pollack MH, Bystritsky A, Kelsey JE, Mangano RM. Efficacy of low and higher dose extended-release venlafaxine in generalized social anxiety disorder: a 6-month randomized controlled trial. Psychopharmacology. 2005;177(3):280-288.

47. Rickels K, Mangano R, Khan A. A double-blind, placebo-controlled study of a flexible dose of venlafaxine ER in adult outpatients with generalized social anxiety disorder. J Clin Psychopharmacol. 2004;24(5):488-496.

48. Liebowitz MR, Mangano RM, Bradwejn J, Asnis G; SAD Study Group. A randomized controlled trial of venlafaxine extended release in generalized social anxiety disorder. J Clin Psychiatry. 2005b;66(2): 238-247.

49. Quitkin FM, Stewart JW, McGrath PJ, Tricamo E. Columbia atypical depression: a subgroup of depressives with better response to MAOI than to tricyclic antidepressants or placebo. Br J Psychiatry. 1993; 163 Suppl 21:30-34.

50. Versiani M, Nardi A, Mundim F, Alves A, Liebowitz M, Amrein R. Pharmacotherapy of social phobia. A controlled study with moclobemide and phenelzine. Br J Psychiatry. 1992;161(3):353-360.

51. Liebowitz MR, Schneier F, Campeas R, et al. Phenelzine vs atenolol in social phobia: A placebo-controlled comparison. Arch Gen Psychiatry. 1992;49(4):290-300. 
52. Heimberg RG, Liebowitz MR, Hope DA, et al. Cognitive behavioral group therapy vs phenelzine therapy for social phobia: 12-week outcome. Arch Gen Psychiatry. 1998;55(12):1133-1141.

53. Gelernter CS, Uhde TW, Cimbolic P, et al. Cognitive-behavioral and pharmacological treatments of social phobia: a controlled study. Arch Gen Psychiatry. 1991;48(10):938-945.

54. Versiani M, Mundim FD, Nardi AE, Liebowitz MR. Tranylcypromine in social phobia. J Clin Psychopharmacol. 1988;8(4):279-283.

55. Nutt DJ, Glue P. Monoamine oxidase inhibitors: rehabilitation from recent research? Br J Psychiatry. 1989;154:287-291.

56. Van Vliet IM, den Boer JA, Westenburg HG. Psychopharmacological treatment of social phobia: clinical and biochemical effects of brofaromine, a selective MAO-A inhibitor. Eur Neuropsychopharmacol. 1992;2(1):21-29.

57. Lott M, Greist JH, Jefferson JW, et al. Brofaromine for social phobia: a multicenter, placebo-controlled, double-blind study. $J$ Clin Psychopharmacol. 1997;17(4):255-260.

58. Fahlén T, Nilsson HL, Borg K, Humble M, Pauli U. Social phobia: the clinical efficacy and tolerability of the monoamine oxidase A and serotonin uptake inhibitor brofaromine: a double-blind placebocontrolled study. Acta Psychiatr Scand. 1995;92(5):351-358.

59. Stein DJ, Cameron A, Amrein R, et al. Moclobemide is effective and well tolerated in the long-term pharmacotherapy of social anxiety disorder with or without comorbid anxiety disorder. Int Clin Psychopharmacol. 2002;17(4):161-170.

60. Schneier FR, Goetz D, Campeas R, Fallon B, Marshall R, Liebowitz MR. Placebo-controlled trial of moclobemide in social phobia. Br J Psychiatry. 1998;172(1):70-77.

61. Oosterbaan DB, van Balkom AJLM, Spinhoven P, van Oppen P, van Dyck R. Cognitive therapy versus moclobemide in social phobia: a controlled study. Clin Psychol Psychother. 2001;8(4):263-273.

62. Noyes RJ, Moroz G, Davidson JRT, et al. Moclobemide in social phobia: a controlled dose-response trial. J Clin Psychopharmacol. 1997;17(4):247-254.

63. Katschnig H. Moclobemide in social phobia. Eur Arch Psychiatry Clin Neurosci. 1997;247(2):71-80.

64. Simpson HB, Schneier FR, Campeas RB, et al. Imipramine in the treatment of social phobia. J Clin Psychopharmacol. 1998;18(2):132-135.

65. Beaumont G. A large open multicentre trial of clomipramine (Anafranil) in the management of phobic disorders. $J$ Int Med Res. 1977; Supp1 5: $116-123$.

66. Ravindran LN, Kim DS, Letamendi AM, Stein MB. A randomized controlled trial of atomoxetine in generalized social anxiety disorder. J Clin Psychopharmacol. 2009;29(6):561-564.

67. Muehlbacher M, Nickel MK, Nickel C, et al. Mirtazapine treatment of social phobia in women: a randomized, double-blind, placebo-controlled study. J Clin Psychopharmacol. 2005;25(6):580-583.

68. Schutters SIJ, Van Megen HJGM, Van Veen JF, Denys DAJP, Westenberg HGM. Mirtazapine in generalized social anxiety disorder: a randomized, double-blind, placebo-controlled study. Int Clin Psychopharmacol. 2010;25(5):302-304.

69. Van Ameringen M, Mancini C, Oakman J, et al. Nefazodone in the treatment of generalized social phobia: a randomized, placebo-controlled trial. J Clin Psychiatry. 2007;68(2):288-295.

70. Mula M, Pini S, Cassano GB. The role of anticonvulsant drugs in anxiety disorders: a critical review of the evidence. J Clin Psychopharmacol. 2007;27(3):263-272.

71. Dooley DJ, Taylor CP, Donevan S, Feltner D. $\mathrm{Ca}^{2+}$ channel [alpha] 2 [delta] ligands: novel modulators of neurotransmission. Trends Pharmacol Sci. 2007;28(2):75-82.

72. Pande AC, Davidson JRT, Jefferson JW, et al. Treatment of social phobia with gabapentin: a placebo-controlled study. J Clin Psychopharmacol. 1999;19(4):341-348.

73. Pande AC, Feltner DE, Jefferson JW, et al. Efficacy of the novel anxiolytic pregabalin in social anxiety disorder: a placebo-controlled, multicenter study. J Clin Psychopharmacol. 2004;24(2):141-149.
74. Feltner DE, Liu-Dumaw M, Schweizer E, Bielski R. Efficacy of pregabalin in generalized social anxiety disorder: results of a doubleblind, placebo-controlled, fixed-dose study. Int Clin Psychopharmacol. 2011;26(4):213-220.

75. Glue P, Loan A, Gale C. New prospects for the drug treatment of generalized anxiety disorder: a systematic review. Curr Drug Ther. 2010;5(2):86-94.

76. Stein M, Ravindran L, Simon N, et al. Levetiracetam in generalized social anxiety disorder: a double-blind, randomized controlled trial. J Clin Psychiatry. 2010;71(5):627-631.

77. Kinrys G, Pollack MH, Simon NM, Worthington JJ, Nardi AE, Versiani M. Valproic acid for the treatment of social anxiety disorder. Int Clin Psychopharmacol. 2003;18(3):169-172.

78. Van Ameringen M, Mancini C, Pipe B, Oakman J, Bennett M. An open trial of topiramate in the treatment of generalized social phobia. J Clin Psychiatry. 2004;65(12):1674-1678.

79. Dunlop BW, Papp L, Garlow SJ, Weiss PS, Knight BT, Ninan PT. Tiagabine for social anxiety disorder. Hum Psychopharmacol. 2007;22(4):241-244.

80. Benítez CIP, Smith K, Vasile RG, Rende R, Edelen MO, Keller MB. Use of benzodiazepines and selective serotonin reuptake inhibitors in middle-aged and older adults with anxiety disorders: a longitudinal and prospective study. Am J Geriatric Psych. 2008;16(1):5-13.

81. Vasile RG, Bruce SE, Goisman RM, Pagano M, Keller MB. Results of a naturalistic longitudinal study of benzodiazepine and SSRI use in the treatment of generalized anxiety disorder and social phobia. Depress Anxiety. 2005;22(2):59-67.

82. Davidson JR, Potts N, Richichi E, Krishnan KR. Treatment of social phobia with clonazepam and placebo. J Clin Psychopharmacol. 1993;13(6):423-428.

83. Versiani M, Nardi AE, Figueira I, Mendlowicz M, Marques C. Doubleblind placebo controlled trial with bromazepam in social phobia. $J$ Bras Psiquiatr. 1997;46(3):167-171. Portuguese.

84. Connor KM, Davidson JRT, Potts NLS, et al. Discontinuation of clonazepam in the treatment of social phobia. J Clin Psychopharmacol. 1998;18(5):373-378.

85. Seedat S, Stein MB. Double-blind, placebo-controlled assessment of combined clonazepam with paroxetine compared with paroxetine monotherapy for generalized social anxiety disorder. J Clin Psychiatry. 2004;65(2):244-248.

86. Comer JS, Mojtabai R, Olfson M. National trends in the antipsychotic treatment of psychiatric outpatients with anxiety disorders. $\mathrm{Am} \mathrm{J}$ Psychiatry. 2011;168(10):1057-1065.

87. Barnett SD, Kramer ML, Casat CD, Connor KM, Davidson JRT. Efficacy of olanzapine in social anxiety disorder: a pilot study. J Psychopharmacol. 2002;16(4):365-368.

88. Vaishnavi S, Alamy S, Zhang W, Connor KM, Davidson JRT. Quetiapine as monotherapy for social anxiety disorder: a placebocontrolled study. Prog Neuropsychopharmacol Biol Psychiatry. 2007;31(7):1464-1469.

89. Davidson J. Pharmacotherapy of social phobia. Acta Psychiatr Scand Suppl. 2003;417:65-71.

90. Koszycki D, Benger M, Shlik J, Bradwejn J. Randomized trial of a meditation-based stress reduction program and cognitive behavior therapy in generalized social anxiety disorder. Behav Res Ther. 2007;45(10):2518-2526.

91. Borge F-M, Hoffart A, Sexton H, Clark DM, Markowitz JC, McManus F. Residential cognitive therapy versus residential interpersonal therapy for social phobia: a randomized clinical trial. $J$ Anxiety Disord. 2008;22(6):991-1010.

92. Stangier U, Schramm E, Heidenreich T, Berger M, Clark DM. Cognitive therapy vs interpersonal psychotherapy in social anxiety disorder: a randomized controlled trial. Arch Gen Psychiatry. 2011;68(7):692-700.

93. Hedman E, Andersson G, Ljótsson B, et al. Internet-based cognitive behavior therapy vs cognitive behavioral group therapy for social anxiety disorder: a randomized controlled non-inferiority trial. PloS One. 2011;6(3):e18001. 
94. Andrews G, Davies M, Titov N. Effectiveness randomized controlled trial of face to face versus Internet cognitive behaviour therapy for social phobia. Aust N Z J Psychiatry. 2011;45(4):337-340.

95. Clark DM, Ehlers A, McManus F, et al. Cognitive therapy versus fluoxetine in generalized social phobia: a randomized placebo-controlled trial. J Consult Clin Psychol. 2003;71(6):1058-1067.

96. Liebowitz MR, Heimberg RG, Schneier FR, et al. Cognitive-behavioral group therapy versus phenelzine in social phobia: Long term outcome. Depress Anxiety. 1999;10(3):89-98.

97. Haug TT, Blomhoff S, Hellstrom K, et al. Exposure therapy and sertraline in social phobia: I-year follow-up of a randomised controlled trial. Br J Psychiatry. 2003;182(4):312-318.

98. Blanco C, Heimberg RG, Schneier FR, et al. A placebo-controlled trial of phenelzine, cognitive behavioral group therapy, and their combination for social anxiety disorder. Arch Gen Psychiatry. 2010;67(3):286-295.

99. Prasko J, Dockery C, Horácek J, et al. Moclobemide and cognitive behavioral therapy in the treatment of social phobia. A six-month controlled study and 24 months follow up. Neuroendocrinol Lett. 2006;27(4):473-481.

100. Knijnik DZ, Blanco C, Salum GA, et al. A pilot study of clonazepam versus psychodynamic group therapy plus clonazepam in the treatment of generalized social anxiety disorder. Eur Psychiatry. 2008;23(8):567-574.
101. Scott K, McGee M, Oakley Browne M, Wells JE. Mental disorder comorbidity in Te Rau Hinengaro: the New Zealand Mental Health Survey (NZMHS). Aust N Z J Psychiatry. 2006;40(10):875-881.

102. Hindmarch I. Cognitive toxicity of pharmacotherapeutic agents used in social anxiety disorder. Int J Clin Pract. 2009;63(7):1085-1094.

103. Curran VH. Benzodiazepines, memory and mood: a review. Psychopharmacology. 1991;105(1):1-8.

104. Glue P, Gale C. Off-label use of quetiapine in New Zealand - a cause for concern? N Z Med J. 2011;124(1336):10-13.

105. Philip NS, Mello K, Carpenter LL, Tyrka AR, Price LH. Patterns of quetiapine use in psychiatric inpatients: an examination of off-label use. Ann Clin Psychiatry. 2008;20(1):15-20.

106. Rush A, Trivedi M, Wisniewski S, et al. Acute and longer-term outcomes in depressed outpatients requiring one or several treatment steps: a STAR* D report. Am J Psychiatry. 2006;163(11):1905-1917.

107. Liebowitz MR. Social phobia. Mod Probl Pharmacopsychiatry. 1987;22:141-173.

108. Marks IM, Mathews AM. Brief standard self-rating for phobic patients. Behav Res Ther. 1979;17(3):263-267.

109. Hamilton M. The assessment of anxiety states by rating. Br J Med Psychol. 1959;32(1):50-55.
Neuropsychiatric Disease and Treatment

\section{Publish your work in this journal}

Neuropsychiatric Disease and Treatment is an international, peerreviewed journal of clinical therapeutics and pharmacology focusing on concise rapid reporting of clinical or pre-clinical studies on a range of neuropsychiatric and neurological disorders. This journal is indexed on PubMed Central, the 'PsycINFO' database and CAS.

\section{Dovepress}

The manuscript management system is completely online and includes a very quick and fair peer-review system, which is all easy to use. Visit http://www.dovepress.com/testimonials.php to read real quotes from published authors. 